\title{
Generalisation of physical habitat-discharge relationships
}

\author{
D.J. Booker and M.C. Acreman \\ Centre for Ecology and Hydrology, Crowmarsh Gifford, Wallingford, Oxon OX10 8BB, UK \\ Email for corresponding author: dobo@ceh.ac.uk
}

\begin{abstract}
Physical habitat is increasingly used worldwide as a measure of river ecosystem health when assessing changes to river flows, such as those caused by abstraction. The major drawback with this approach is that defining precisely the relationships between physical habitat and flow for a given river reach requires considerable data collection and analysis. Consequently, widely used models such as the Physical Habitat Simulation (PHABSIM) system are expensive to apply. There is, thus, a demand for rapid methods for defining habitat-discharge relationships from simple field measurements. This paper reports the analysis of data from 63 sites in the UK where PHABSIM has been applied. The results demonstrate that there are strong relationships between single measurements of channel form and river hydraulics and the habitat available for target species. The results can form the basis of a method to estimate sensitivity of physical habitat to flow change by visiting a site at only one flow. Furthermore, the uncertainty in estimates reduces as more information is collected. This allows the user to select the level of investment in data collection appropriate for the desired confidence in the estimates. The method is demonstrated using habitat indicators for different life stages of Atlantic salmon, brown trout, roach and dace.
\end{abstract}

Keywords: physical habitat, river management, habitat suitability, rapid habitat assessment.

\section{Introduction}

Many factors influence the health of river ecosystems including temperature, oxygen, light and flow (Hynes, 1970; Giller and Malmqvist, 1998; Norris and Thoms, 1999). All elements of a flow regime are important, including floods, average and low flows (Poff et al., 1997; Richter et al., 1997; Junk et al., 1989). However, apart from through dilution effects, flow rate $\left(\mathrm{m}^{3} \mathrm{~s}^{-1}\right)$ is only a surrogate variable; it is the water depth and velocity in a river, created by the interaction between flow rate and channel morphology, that provides physical habitat for plants, invertebrates and fish. Jowett (1992) found that the amount of physical habitat was an important determinant of trout abundance, Gore et al. (1998) found relationships between physical habitat and actual benthic community diversity and Gallagher and Gard (1999) found a positive correlation between physical habitat and spawning density of salmon.

The direct relationship between physical habitat and flow provides a means for assessing the ecological impact of changing the flow regime of a river (Beecher et al., 1993; Cavendish and Duncan, 1986; Jowett, 1990). However, assessment of river flow management options often involves assessing scenarios that fall outside the range of observed conditions, thus, predictive models are required. The Physical Habitat Simulation (PHABSIM) system (Bovee, 1982; Bovee et al., 1998) was the first systematic modelling framework to be developed and many models based on a similar concept have been produced including CASiMIR in Germany (Jorde, 1996; Eisner et al., 2005), EVHA in France (Ginot, 1995), RHYbasiM in New Zealand (Jowett, 1989) and RSS in Norway (Killingtviet and Harby, 1994). Essentially these models quantify the relationship between physical habitat for a given site defined in terms of the combination of depth, velocity and substrate/cover at a particular discharge (e.g. Johnson et al., 1993; Elliott et al., 1996). Criticisms of this approach include lack of biological realism (Orth, 1986) and mechanism (Mathur et al., 1985; Booker et al., 2004). Nevertheless, the models have been applied throughout the world (Dunbar and Acreman, 2002), primarily to assess impacts of abstraction or river impoundment. However, the method has also been used to assess the effects of channel restoration and modification 
Table 1. Site Details.

\begin{tabular}{|c|c|c|c|c|c|c|}
\hline Site & River name & Site name & No. of cross-sections & No. of calibrations & Easting & Northing \\
\hline 1 & Tame & Highly modified & 4 & 3 & 40290 & 29270 \\
\hline 2 & Tame & Less modified & 5 & 4 & 40300 & 29250 \\
\hline 3 & Rea & Concrete lined & 5 & 4 & 40630 & 28350 \\
\hline 4 & Rea & Gabion lined & 5 & 4 & 40610 & 28290 \\
\hline 5 & Cole & Modified & 4 & 3 & 41750 & 28760 \\
\hline 6 & Cole & Restored & 5 & 3 & 41720 & 28790 \\
\hline 8 & Exe & Warren Farm & 10 & 3 & 27920 & 14060 \\
\hline 9 & Hodder & Hodder Bank & 6 & 3 & 36550 & 44870 \\
\hline 10 & Gwash & Belmesthorpe & 13 & 2 & 50410 & 31050 \\
\hline 11 & Itchen & U/S of Highbridge & 10 & 2 & 44670 & 12130 \\
\hline 12 & Lambourn & Hunt's Green & 12 & 3 & 44350 & 17010 \\
\hline 13 & Lymington & $\mathrm{U} / \mathrm{S}$ of Balmerlawn & 12 & 3 & 43020 & 10330 \\
\hline 15 & Wye & Pant Mawr & 12 & 3 & 28470 & 28230 \\
\hline 16 & Wey & Pre-restoration & 12 & 2 & 48500 & 14710 \\
\hline 17 & Wey & Post-restoration & 14 & 3 & 48500 & 14710 \\
\hline 18 & Wylye & Chitterne Brook lower & 5 & 3 & 39710 & 13980 \\
\hline 19 & Wylye & Chitterne Brook upper & 6 & 3 & 39730 & 14104 \\
\hline 20 & Wylye & Stockton / Glebe Farm & 11 & 3 & 39850 & 13840 \\
\hline 21 & Wylye & Longbridge Deverill & 9 & 2 & 38738 & 14332 \\
\hline 23 & Wylye & Upper Wylye (lower site) & 3 & 3 & 38640 & 13910 \\
\hline 24 & Wylye & Upper Wylye (middle site) & 9 & 3 & 38460 & 13720 \\
\hline 27 & Allen & Upper & 11 & 3 & 40070 & 10800 \\
\hline 28 & Allen & Lower & 7 & 3 & 40030 & 10750 \\
\hline 29 & Bray & Leehamford & 12 & 3 & 26780 & 13990 \\
\hline 30 & Barle & Perry Weir & 9 & 3 & 29307 & 12546 \\
\hline 31 & Piddle & Upper & 12 & 3 & 37450 & 9500 \\
\hline 32 & Piddle & Lower / Briantspuddle & 9 & 3 & 38230 & 9330 \\
\hline 33 & Piddle & Devils Brook & 10 & 2 & 37790 & 9900 \\
\hline 34 & Piddle & Higher Hyde & 11 & 4 & 38596 & 9117 \\
\hline 35 & Walkham & Ward Bridge & 10 & 4 & 25440 & 7230 \\
\hline 36 & Senni & Abersenni & 12 & 3 & 29300 & 22680 \\
\hline 40 & Carron & New Kelso & 10 & 3 & 19420 & 84280 \\
\hline 41 & Ordie Burn & East Mains & 7 & 3 & 30820 & 73250 \\
\hline 48 & Tavy & Nat Tor $(1 \mathrm{~A})$ & 8 & 3 & 25460 & 8220 \\
\hline 49 & Tavy & Hill Bridge (1B) & 3 & 3 & 25330 & 8040 \\
\hline 50 & Tavy & Horndon Bridge (2) & 12 & 3 & 25220 & 7950 \\
\hline 51 & Tavy & Brook Mill (3) & 10 & 3 & 24750 & 7250 \\
\hline 52 & Kennet & Axford (upstream) & 10 & 3 & 42360 & 16980 \\
\hline 53 & Kennet & Axford (downstream) & 15 & 3 & 42390 & 16990 \\
\hline 54 & Kennet & Ramsbury & 10 & 3 & 42720 & 17140 \\
\hline 201 & Babingley & Site $\mathrm{G}$ & 5 & 3 & 57040 & 32550 \\
\hline 202 & Glen (West) & Creeton & 5 & 3 & 50150 & 31960 \\
\hline 204 & Glen (West) & Shillingthorpe & 5 & 3 & 50560 & 31125 \\
\hline 205 & Glen (East) & Edenham & 5 & 3 & 50630 & 32230 \\
\hline 206 & Glen (East) & Braceborough & 5 & 3 & 50810 & 31350 \\
\hline 207 & Wissey & Bodney Bridge & 7 & 3 & 58285 & 29884 \\
\hline 208 & Wissey & Chalk Hill Farm & 7 & 3 & 58400 & 29770 \\
\hline 209 & Wissey & Didlington Gravel & 5 & 3 & 58020 & 29460 \\
\hline 210 & Wissey & Didlington Sand & 7 & 3 & 57880 & 29530 \\
\hline 211 & Wissey & Langford Gravel & 7 & 3 & 58400 & 29670 \\
\hline 212 & Wissey & Langford Sand & 7 & 3 & 58380 & 29640 \\
\hline 213 & Wissey & Northwold & 7 & 3 & 57560 & 29780 \\
\hline 214 & Upper Derwent & River Ashop / River Alport & 6 & 3 & 41490 & 38920 \\
\hline 215 & Upper Derwent & River Noe & 6 & 3 & 41550 & 38650 \\
\hline 216 & Upper Derwent & Jaggers Clough & 6 & 3 & 41610 & 38650 \\
\hline 217 & Upper Derwent & River Derwent & 6 & 3 & 41970 & 38460 \\
\hline 218 & Upper Severn & Dolwen & 10 & 3 & 29920 & 28515 \\
\hline 219 & Churnet & d/s Tittesworth Reservoir & 9 & 5 & 39935 & 35860 \\
\hline 220 & Ure & d/s Kilgram Bridge & 8 & 3 & 41940 & 48560 \\
\hline 221 & Pant/Blackwater & Great Sampford (site 1) & 5 & 3 & 56470 & 23500 \\
\hline 222 & Pant/Blackwater & Little Sampford (site 2) & 6 & 3 & 56550 & 23385 \\
\hline 223 & Pant/Blackwater & Kelvedon (site 4) & 4 & 3 & 57945 & 22425 \\
\hline 225 & Tywi & Rhandirmwyn & 10 & 3 & 27780 & 24355 \\
\hline
\end{tabular}


(Acreman and Elliott, 1996; Booker and Dunbar, 2004). PHABSIM in particular has become a legal requirement for many impact studies in the USA (Reiser et al., 1989) and a standard tool employed by the Environment Agency of England and Wales to define the sensitivity of rivers to abstraction, which is required for the development of Catchment Abstraction Management Strategies (Environment Agency, 2000) and assessment of ecological status in the European Water Framework Directive (Acreman et al., 2005).

The PHABSIM system has been applied to many UK rivers including the Allen (Johnson et al., 1995), Piddle (Strevens, 1999), Wylye (Dunbar et al., 2000), Ordie Burn (Elliott et al., 1999) and Kennet (McPherson, 1997). Most applications have been on physical habitat availability for fish, although macroinvertebrates (Gore et al., 1998) and macrophytes (Hearne et al., 1994), which have measurable physical habitat requirements, have been studied. Most studies have followed national guidelines (Elliott et al., 1996) which include (1) definition of river sectors and species/life stages of interest; (2) specification of habitat suitability indices (HSIs) for the species/life stages; (3) identification and mapping of habitats within the sectors of interest; (4) selection of cross-sections which represent replicates of each habitat type; (5) collection of model calibration data (water surface elevation, depth and velocity) at, at least, three different flows; (6) calibration of hydraulic models; (7) calculation of physical habitat for the species/ life stages of interest for a range of flows. Physical habitat is expressed as Weighted Usable Area (WUA) in $\mathrm{m}^{2}$ per $1000 \mathrm{~m}$ of river channel. Graphs of WUA versus discharge are a fundamental output from PHABSIM and the slope of the relationship defines the sensitivity to flow change of physical habitat for the river sector.

Full physical habitat modelling is site specific and requires extensive collection of field data, including velocities, depths and water surface elevations at several different flows (Bovee, 1982). Regional approaches to defining habitatdischarge relationships from fewer simple measurements of river channel dimensions have been developed for rivers in France (Lamouroux and Capra, 2002), USA (Kennard, 2000) and New Zealand (Lamouroux and Jowett, 2005).

This paper describes the analysis of habitat-discharge relationships using data from rivers in the UK. A method is given for making habitat assessments about the site of interest, using various levels of information ranging from catchment characteristics to field measurements recorded at a single flow. The trade-off between the uncertainty associated with results and the nature of the field measurements is investigated.

\section{Method}

\section{SITES}

A list of sites where PHABSIM studies have been undertaken in the UK was compiled. Of the 78 sites identified, 12 sites were rejected because either data were unobtainable or insufficient data were available to calibrate the hydraulic models. This left 66 sites for which one-dimensional hydraulic models could be defined following the methods given in Elliott et al. (1996). Most cross-sections gave a level of calibration of $\pm 0.04 \mathrm{~cm}$ when comparing observed and calculated water levels, although differences of $\pm 0.08 \mathrm{~cm}$ were found for one cross-section at the Glen Edenham and Kennet Axford Upstream sites respectively.

Flow duration curves based on daily flows were calculated for each site using the Low Flows 2000 software system (Holmes et al., 2002a,b, 2005). In total, 41 flows were simulated for each site, based on points on the flow duration curve for that site ranging from $\mathrm{Q}_{99}$ to $\mathrm{Q}_{2}$ for each specific catchment. These flows were defined as being every fifth percentile on the flow duration curve and every percentile for the five percentiles either side of $Q_{95}$ and $Q_{70}$. Of the 66 sites, natural flow duration curves could not be obtained for two (South Winterbourne, Upper and Lower) as they did not have definable contributing catchment areas (these sites are side channels of the River Frome). A flow duration curve was also unobtainable for the Glenwhirry in Northern Ireland, where Low Flows 2000 is not set up. Therefore, 63 sites (Fig. 1) and a total of 508 cross-sections (Table 1) were included in further analysis. Data from Low Flows 2000 (Holmes et al., 2005), the Flood Estimation Handbook (Institute of Hydrology, 1999) and Intelligent River Network (Dawson et al., 2002) were used to generate catchment characteristics for each site (Table 2). Cross-sectional-based hydraulic modelling of depths and velocities at each site allowed a suite of hydraulic properties to be calculated for each cross-section (Table 3). Details of the methods used to calculate channel asymmetry are given in Milne (1983).

\section{HABITAT SUITABILITY INDICES}

Habitat Suitability Indices (HSIs) were available for 10 different species and life stages (Table 4). The most comprehensive preference indices currently available for juvenile salmonids, presented in Dunbar et al. (2001; Fig. 2 ), were developed from a database of over 7500 observations of fish habitat use and availability from 16 sites in Devon, South Wales and Dorset. These sites included rivers on Chalk catchments and upland rivers. The majority of observations of fish were made by snorkellers, although electro-fishing was used in very shallow water. In this study, 


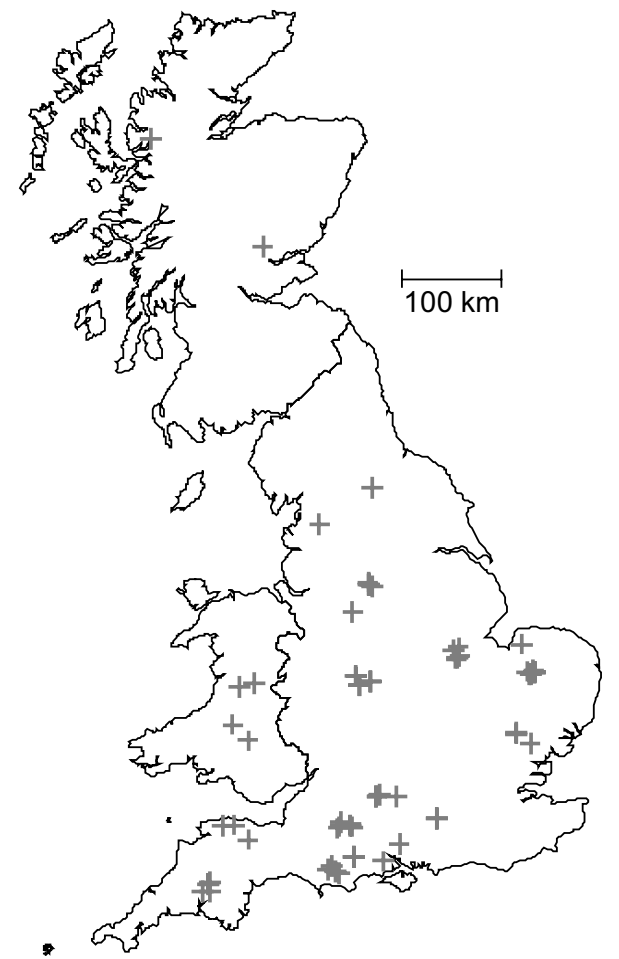

Fig. 1. Map of England, Scotland and Wales with sites.
Table 2. Catchment variables.

\begin{tabular}{|c|c|}
\hline Variable & Description \\
\hline Altitude & Altitude of site \\
\hline BasArea & Catchment area \\
\hline BFI & Base Flow Index \\
\hline Distance & Distance from source \\
\hline Easting & x co-ordinate \\
\hline Northing & y co-ordinate \\
\hline PotEvap & $\begin{array}{l}\text { Potential evaporation for standard period 1961- } \\
1990 \mathrm{~mm} \mathrm{yr}^{-1}\end{array}$ \\
\hline Q2 & Mean daily discharge exceeded $2 \%$ of the time \\
\hline Q50 & Mean daily discharge exceeded $50 \%$ of the time \\
\hline Q70 & Mean daily discharge exceeded $70 \%$ of the time \\
\hline SAAR & $\begin{array}{l}\text { Standard period average annual rainfall 1961- } \\
1990\end{array}$ \\
\hline Slope & Valley slope at site \\
\hline SourceAlt & Altitude of source \\
\hline Type & WFD System A classification type \\
\hline
\end{tabular}

Table 3. Cross-sectional variables.

\begin{tabular}{|c|c|c|}
\hline Variable & Description & How measured \\
\hline \multicolumn{3}{|c|}{ FLOW DEPENDENT HYDRAULIC VARIABLES } \\
\hline$D$ & Mean Depth & Wading rod to measure depth across cross-section \\
\hline$V$ & Mean Velocity & Current meter across cross-section of interest \\
\hline$F$ & Froude Number $F=V / \sqrt{g D}$ & See $\mathrm{V}$ and $\mathrm{D}$ \\
\hline$R$ & $\begin{array}{l}\text { Reynolds Number } R=\rho V D / \mu \\
\text { Where } r \text { is density and } \mathrm{m} \text { is viscosity }\end{array}$ & See $\mathrm{V}$ and $\mathrm{D}$ \\
\hline$A$ & Cross-sectional area & Wading rod and tape measure across cross-section of interest \\
\hline$A_{\text {syml }}$ & $\begin{array}{l}\text { (area to right of channel centre - area } \\
\text { to left of channel centre) / sectional area }\end{array}$ & Wading rod and tape measure across cross-section of interest \\
\hline$A_{\text {sym } 2}$ & $\begin{array}{l}2 * \text { distance from channel centre to } \\
\text { deepest point in the section } * \text { (maximum } \\
\text { depth - mean sectional depth) / sectional area }\end{array}$ & Wading rod and tape measure across cross-section of interest \\
\hline$D_{\max }$ & Maximum Depth & One wading rod measurement at cross-section of interest \\
\hline$V_{\max }$ & Maximum Velocity & One current meter measurement at cross-section of interest \\
\hline$W_{W}$ & Wetted width & Tape measure at cross-section of interest \\
\hline$W_{P}$ & Wetted perimeter & Tape measure at cross-section of interest \\
\hline$Q_{i}$ & $\begin{array}{l}\text { Discharge, where present subscript indicates } \\
\text { for which flow percentile }\end{array}$ & $\begin{array}{l}\text { Current meter across one section at the site or from nearest gauging } \\
\text { station }\end{array}$ \\
\hline \multicolumn{3}{|c|}{ FLOW INDEPENDENT VARIABLES } \\
\hline$W_{W 2}$ & Bankfull width & Tape measurement of bankfull width at cross-section of interest \\
\hline
\end{tabular}


Table 4. Species and life stages of habitat suitability indices.

\begin{tabular}{lll}
\hline $\begin{array}{l}\text { HSI } \\
\text { number }\end{array}$ & Species & $\begin{array}{l}\text { Life stage or } \\
\text { body length }\end{array}$ \\
\hline 1 & Salmon (Salmo salar L.) & $0-7 \mathrm{~cm}$ \\
2 & Salmon (Salmo salar L.) & $8-20 \mathrm{~cm}$ \\
3 & Trout (Salmo trutta L.) & $0-7 \mathrm{~cm}$ \\
4 & Trout (Salmo trutta L.) & $8-20 \mathrm{~cm}$ \\
5 & Roach (Rutilus rutilus L.) & Adult \\
6 & Roach (Rutilus rutilus L.) & Juvenile \\
7 & Roach (Rutilus rutilus L.) & Fry \\
8 & Dace (Leuciscus leuciscus L.) & Adult \\
9 & Dace (Leuciscus leuciscus L.) & Juvenile \\
10 & Dace (Leuciscus leuciscus L.) & Fry \\
\hline
\end{tabular}

the HSIs were developed by calculating habitat preference at each site, and pooling the results. The data on which these HSIs were based included observations of fish in water less than $1 \mathrm{~m}$ deep. Dunbar et al. (2001) showed that up to $1 \mathrm{~m}$ depth there was no evidence of fish avoiding deep water, providing velocities were suitable. However, beyond $1 \mathrm{~m}$, no data are available to describe preference. Predictions of habitat quality in water over $1 \mathrm{~m}$ depth represent an extrapolation of the HSIs beyond any observed data. For this work, the habitat suitability for depth was extended to $3 \mathrm{~m}$ but not beyond, based on the fact that observations of habitat utilisation in deep fast flowing water have been made in other studies (Beecher, 1990). HSIs were also available for dace and roach (see Booker and Dunbar 2004, after Johnson et al., 1993). These indices were all derived from expert opinion, supported by previous literature on habitat use.

Data on substrate type were available from the various studies. These data were collected by a variety of methods and recorded in different formats, reconciliation of which in a consistent scheme was not possible. Therefore, habitat suitability was assessed based only on available depth and velocity. Substrate is less critical for the juvenile life stage than for others such as spawning (Hughes 1992; Metcalfe et al., 1997; Greenberg and Giller, 2001).

\section{HABITAT-DISCHARGE RELATIONSHIPS}

For each of the sites, plots of WUA $v$. discharge were produced; the horizontal axis $\left(P_{r e v}\right)$ was the percentage of time discharge equal to, or less than, the specified flow, i.e. 0 to $100 . P_{r e v}$ is, therefore, equivalent to the reversed flow percentile. The vertical axis was WUA/wetted width at $\mathrm{Q}_{2}$ $\left(W_{U A} / W_{W 2}\right)$, i.e. 0 to $1 . \mathrm{Q}_{2}$ was assumed to be broadly equivalent to bank-full discharge. This method of normalisation includes the effects of changes in width on changes in habitat as discharge increases. Various curve shapes derived from different equations were tested and a three parameter quadratic equation (Eqn. 1) was a good fit to data at all sites for all HSIs. Figure 3 a shows that the root mean square error of the proportion of the river that provided suitable habitat was below $12 \%$ for all sites and all HSIs.

$$
W_{U A} / W_{W 2}=a+b P_{r e v}+c P_{r e v}^{2}
$$

The three parameters ( $a, b$ and $c$ ) can be interpreted as follows: the intercept $(a)$ describes where the curve crosses $\mathrm{x}=0$; the multiple $(b)$ describes the rate at which habitat is rising at $P_{r e v}=0$; and the coefficient on the squared term (c) describes how bell-shaped the curve is. Therefore, $a$ relates to the proportion of habitat at the lowest natural flow at that site, $b$ to the rate of change of the proportion of habitat at

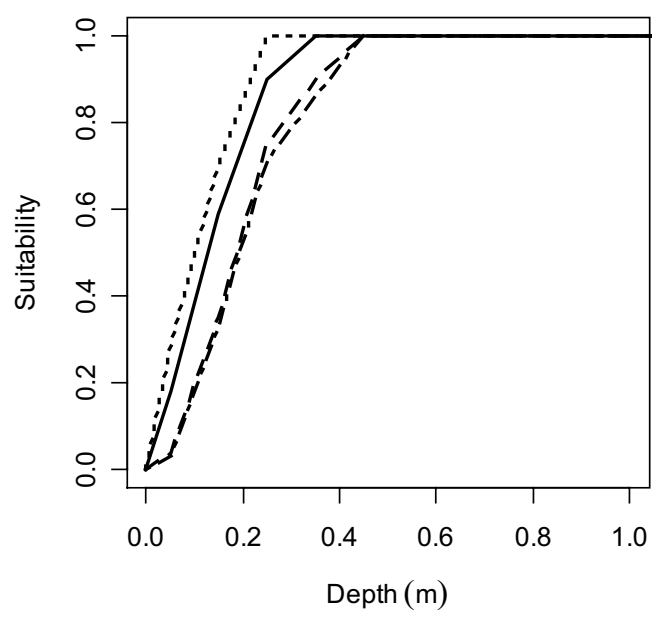

Fig. 2. Suitability for juvenile salmonids (after Dunbar et al., 2001). 
a) Fitted quadratic

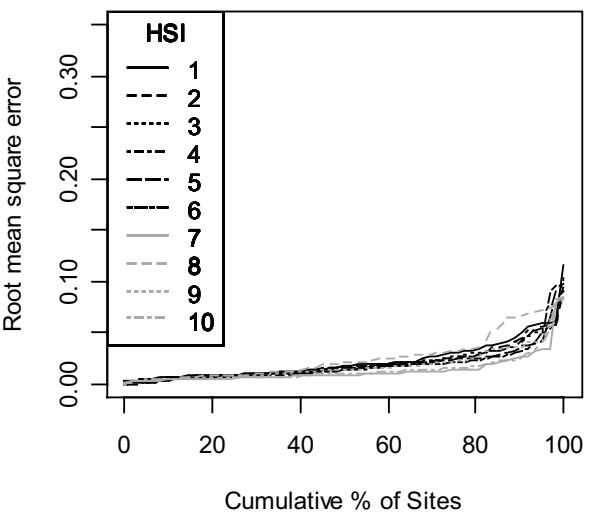

c) Quick set

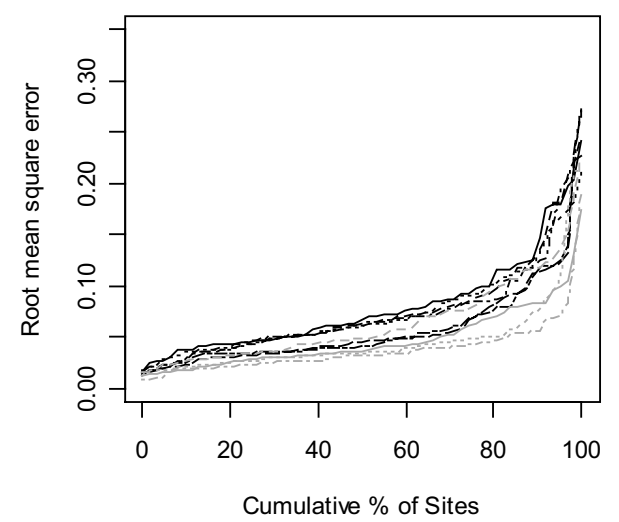

b) Catchment variables

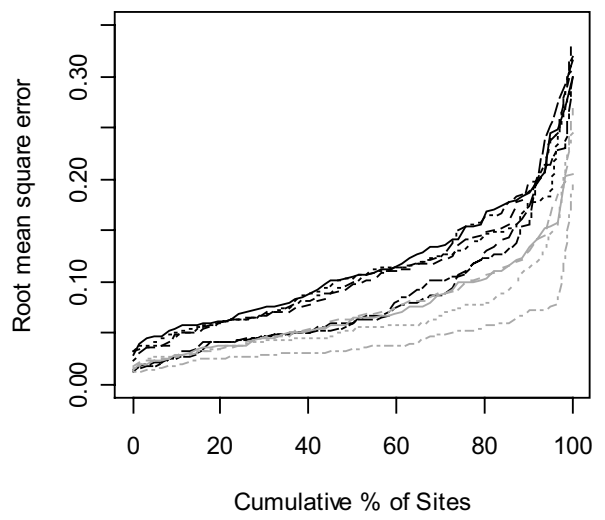

d) Full set

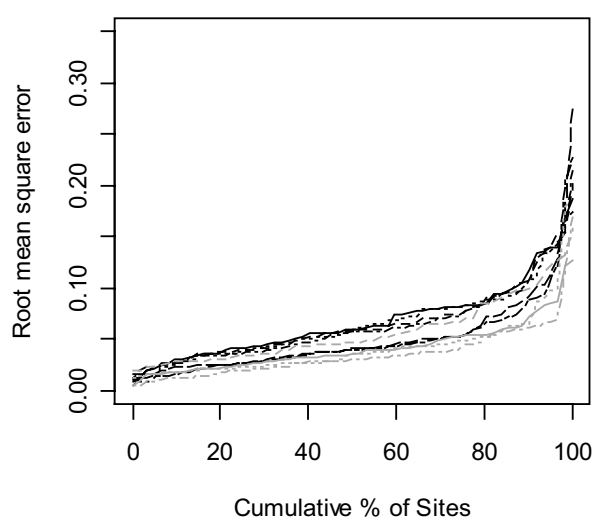

Fig.. 3. Cumulative plots of root mean square error between estimated habitat and habitat predicted by PHABSIM for each site.

low flows and $c$ to the rate of change of the proportion of habitat at high flows compared to low flows. Therefore, $b$ is the parameter which best describes sensitivity to abstraction at low flows.

Application to the sites of the Lamouroux and Capra (2002) model, focused on use of the Reynolds number at a site, proved to be a poor fit to the shape of the curves because Lamouroux and Capra (2002) used very different HSIs to those used in the UK, so their habitat $v$. discharge curves were dissimilar. Statistical analyses were, therefore, used to search for explanatory variables to estimate the form of the $W_{U A} / W_{W 2} v . P_{r e v}$ curves. The ability to predict $W_{U A} / W_{W 2} v$. $P_{\text {rev }}$ curves was based on: (a) catchment information; (b) all cross-sectional hydraulic measurements, including those taken using a current meter; and (c) cross-sectional hydraulic measurements that could be measured with only a wading rod and a tape measure, i.e. during a field visit to the site of a few hours. These sets of information are referred to as the Full and Quick set of catchment variables, respectively.

Assessment of the individual $W_{U A} / W_{W 2} v . P_{r e v}$ curves for each cross-section from all sites revealed that some sites have large variations in hydraulic properties, because many sites contain a variety of physical habitat types, such as pools, riffles and glides (Maddock, 1999). For example, the variation in parameter $a$ is shown in Fig. 4 for each of the cross-sections, grouped by site. Some sites are composed of homogenous cross-sections, such as where the river has been channelised. The next stage of the analysis compared the shape of the $W_{U A} / W_{W 2}$ v. $P_{r e v}$ curves with hydraulic characteristics at a given flow for each cross-section.

\section{STATISTICAL METHODS}

Variables within the data set were plotted against each other for visual inspection. A principal component analysis (Venables and Ripley, 2002) was applied to the entire dataset to explore which variables could be used to explain the variations across the 63 sites and 508 cross-sections. As multi-collinearity presents instabilities in many statistical approaches, such as stepwise multi-linear regression, a 


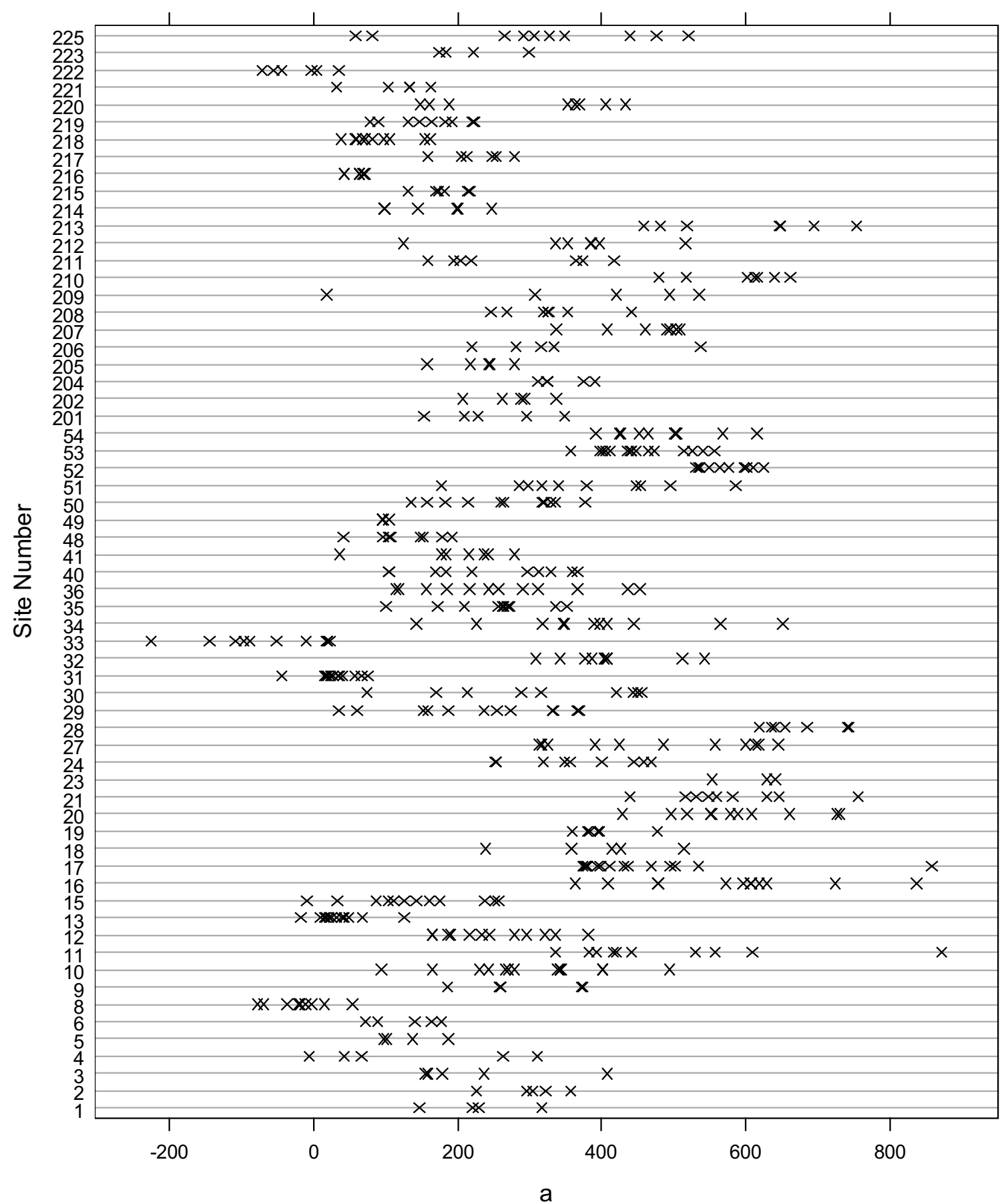

Fig. 4. Parameter a for HSII.

hierarchical partitioning method (Chevan and Sutherland, 1991; Hatt et al., 2004) was also applied. This method calculates goodness-of-fit measures for the entire hierarchy of models, using all combinations of the independent variables to identify the most likely causal factors (MacNally, 2000).

Stepwise multi-linear regression was used to assess the strength of the relationships between $a, b$ and $c$ and: (a) the catchment variables; (b) the Full set; and (c) the Quick set of hydraulic variables at specified discharges. This analysis included assessment of the significance of the relationships and the existence of curvature within the relationships. The Akaike information criterion was used to apply a penalised log likelihood method to evaluate the trade-off between degrees of freedom and fit of the model as more explanatory parameters are added into it (Crawley, 2002). 
The effect of bias in the data sets was investigated using standard model evaluation plots, by comparing model residuals with fitted values (Crawley, 2002) and by comparing leverage with Cook's distance (Belsley et al., 1980). Leverage and Cook's distance are measures of influence that highlight particularly influential data points in the data set (Crawley, 1993). Standard non-parametric bootstrap re-sampling with replacement (Davison and Hinkley, 1997) was used to apply the same stepwise multilinear regression method to 100 randomly sampled versions of the data set to assess the stability of the results.

\section{Results}

\section{VISUAL INSPECTION}

Figure 5 shows the relationships between $a, b$ and $c$ and some of the hydraulic parameters at $\mathrm{Q}_{95}$ for all cross-sections. There is a strong correlation between $b$ and $c$. This is because the shape of the $W_{U A} / W_{W 2}$ v. $P_{r e v}$ curves is constrained between 0 and $1\left(W_{U A} / W_{W 2}\right)$ and 0 and $100\left(P_{r e v}\right)$. Thus, crosssections that have rapidly increasing habitat at low flows also have more rapidly decreasing habitat at high flows. In contrast, cross-sections with decreasing habitat at low flows have increasing habitat at high flows. There are clearly relationships between the model parameters and the hydraulic parameters. However, there are also co-variances between the different hydraulic parameters. For example, depth increases as width increases and high velocities typically occur only in conjunction with shallow depths.

\section{PRINCIPAL COMPONENTS ANALYSIS}

Figure 6a suggests relationships between the shape of the $W_{U A} / W_{W 2}$ v. $P_{r e v}$ curves and catchment characteristics for the sites. The relative roles of variations in catchment size and climate are reflected in the relationships between the different catchment characteristics. Parameter $b$ is positively aligned with slope and altitude, while $c$ is more strongly aligned with climatological variables such as potential

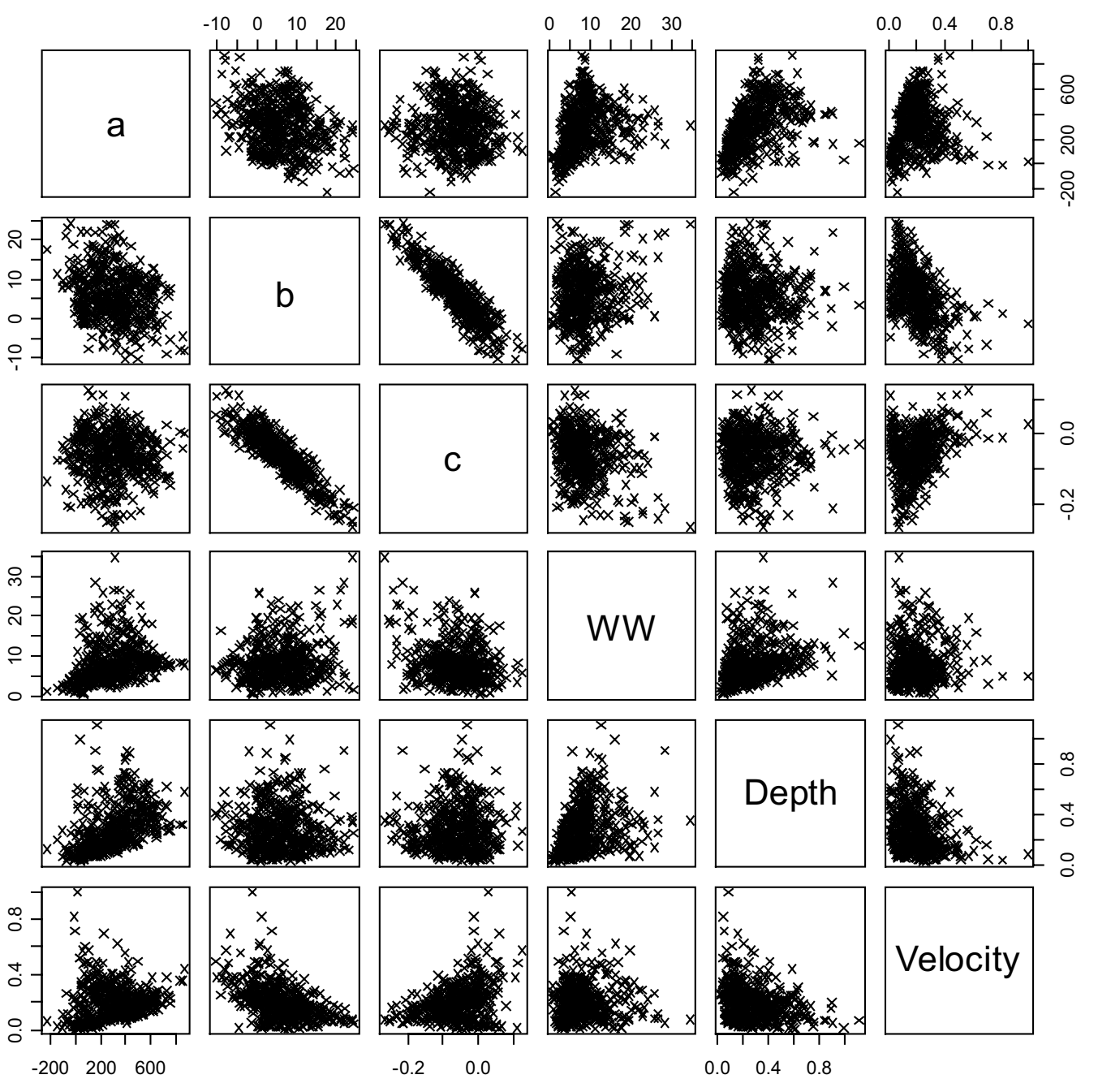

Fig. 5. Parameters a, b and c against hydraulic parameters for $Q_{95}$. 
(a)

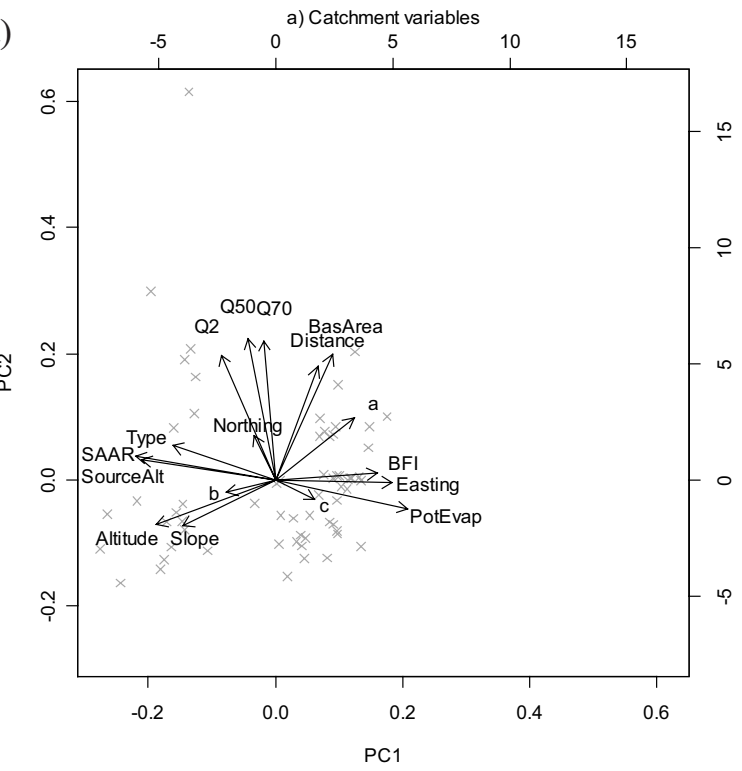

(b)

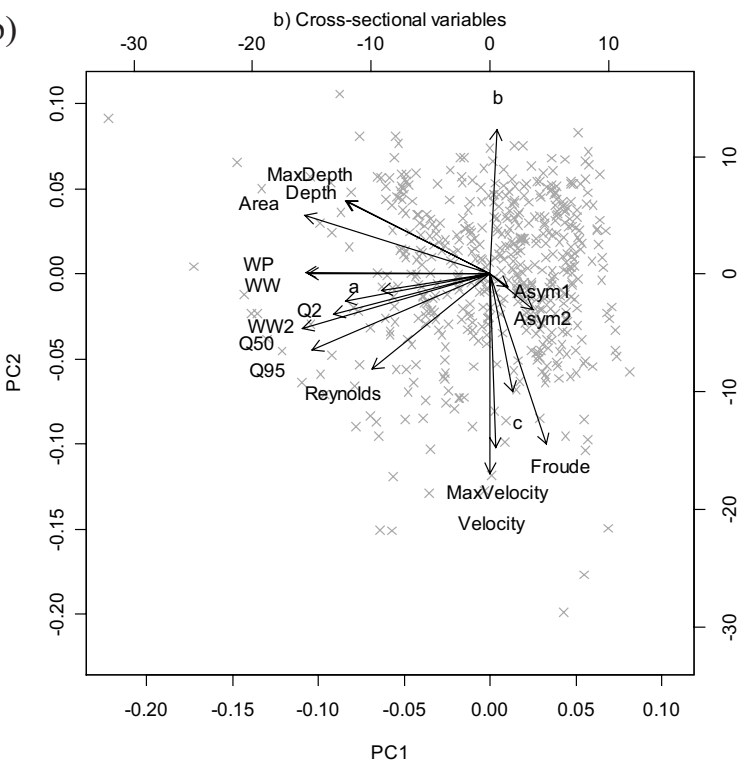

Fig. 6. The first two components of a principal components analysis in relation to $\mathrm{a}, \mathrm{b}$, and $\mathrm{c}$ for HSII: (a) catchment variables and; (b) crosssectional variables at $Q_{9 .}$. Primary axis relate to positions of variables, secondary axis relate to positions of the observations.

evaporation and rainfall.

Results from the principal components analysis of the cross-sectional data show that the first component of the data set was dominated by scale dependent variables (Fig. 7b). For example, discharge, width and cross-sectional area all tend to increase with distance downstream. The second component was dominated by scale independent variables such as velocity. The closeness of the direction of the arrows in Fig. 7 indicates the correlation between the variables. For example, wetted width and wetted perimeter are correlated strongly, so wetted perimeter was omitted from further analysis. The correlation between Depth and maximum depth, is also strong while that between wetted width and velocity is weak. Parameter $a$ is strongly orientated with the first component but $b$ and $c$ are orientated with the second component; thus the proportion of the river which is suitable at low flows is positively correlated with the size of the river. The sensitivity to abstraction at low flows (represented by $b$ ) is scale independent and negatively correlated with velocity. Parameter $c$ is also scale independent but positively correlated with velocity.

\section{HIERARCHICAL PARTITIONING}

Figure 7 shows the percentage distribution of independent effects of the catchment variables on $a, b$ and $c$, as calculated from hierarchical partitioning. All 10 of the variables shown have some level of independent explanatory power on either $a, b$ or $c$. However, Base Flow Index (BFI) has substantially greater independent explanatory power in relation to $a, b$ and $c$ than the other catchment variables. BFI also has the largest dependent effects. This demonstrates that there are considerable collinearities between BFI and the other catchment variables.

Figure 7 also shows the percentage distribution of independent effects of the cross-sectional variables on $a, b$ and $c$, as calculated from hierarchical partitioning. All 12 variables have some level of independent explanatory power on $a, b$ and $c$. However, Reynolds number, depth and discharge have substantially greater independent explanatory power in relation to $a$ than the other hydraulic variables. Velocity, maximum velocity, Reynolds number, Froude number and discharge all have high independent explanatory power in relation to $b$. For $c$ the situation is less clear, with maximum velocity, wetted width, velocity, Froude number and Reynolds number all exhibiting independent explanatory power. Considerable collinearities within the cross-sectional variables are particularly evident between discharge, depth and Reynolds number in relation to $a$. Collinearities within velocity, maximum velocity, Reynolds number and Froude number are also evident in relation to $b$ and $c$. These results, together with those from the PCA, indicate that velocity, maximum velocity, Reynolds number and Froude number are strongly interrelated and may have similar relationships with $a, b$ and $c$.

\section{STEPWISE REGRESSION}

The values for $\mathrm{a}, \mathrm{b}$ and $\mathrm{c}$ were calculated from the catchment variables, as well as from the Quick and Full sets of crosssectional variables using the regression models. Although there are variations between sites and between the HSIs, 
D.J. Booker and M.C. Acreman
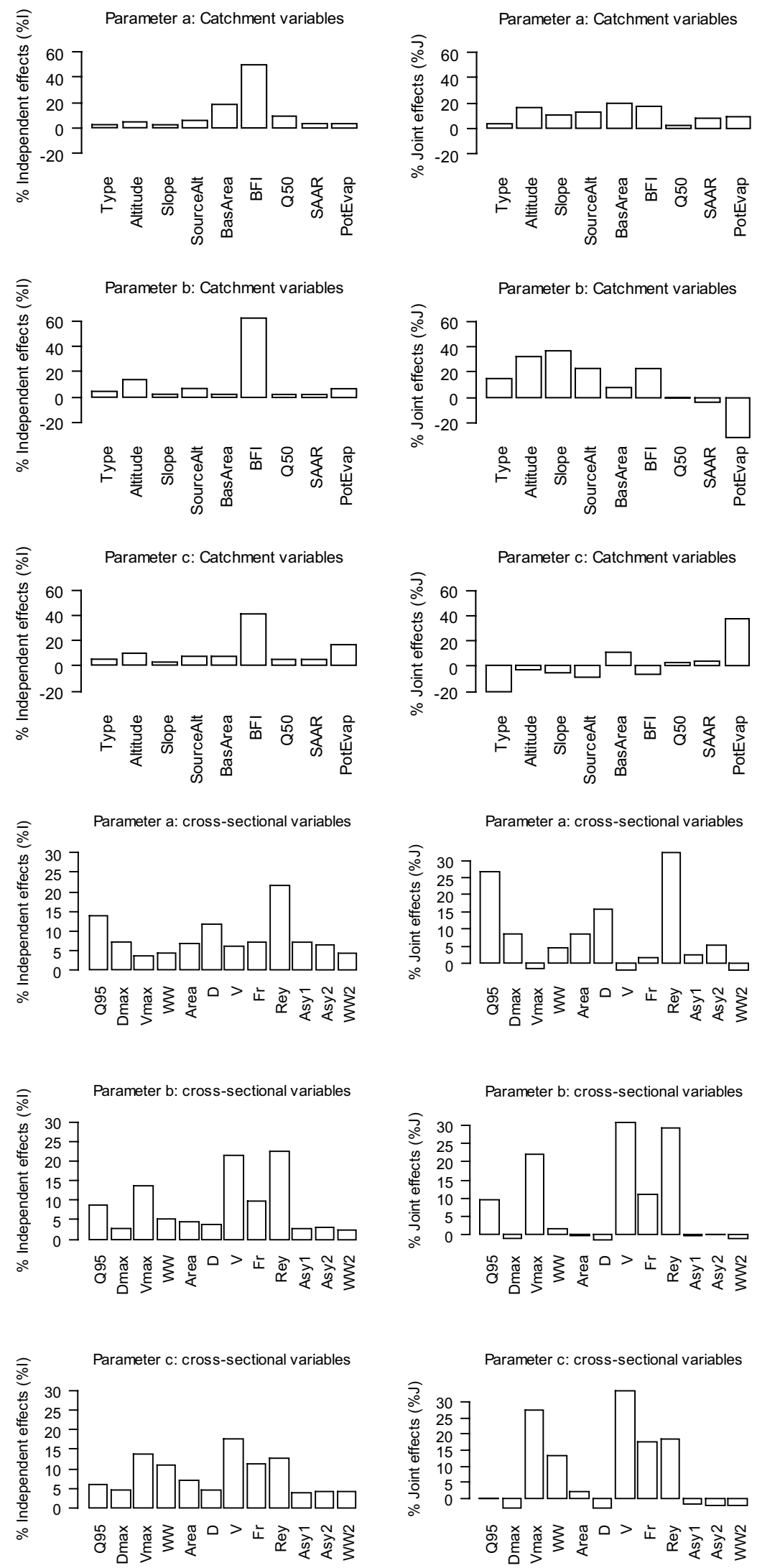

Fig. 7. Percentage-distribution of independent and joint effects calculated from hierarchical partitioning for a, b and $\mathrm{c}$ for HSII using catchment variables and cross-sectional variables at $Q_{95}$ 
results agree well with the predictions of physical habitat calculated using PHABSIM (Figs. 3 and 8). This shows that the shape of the $W_{U A} / W_{W 2} v . P_{r e v}$ curve can be estimated from catchment characteristics or cross-sectional measurements taken at only one flow, in this case $\mathrm{Q}_{95}$. The root mean square error values indicate that confidence in estimating the shape

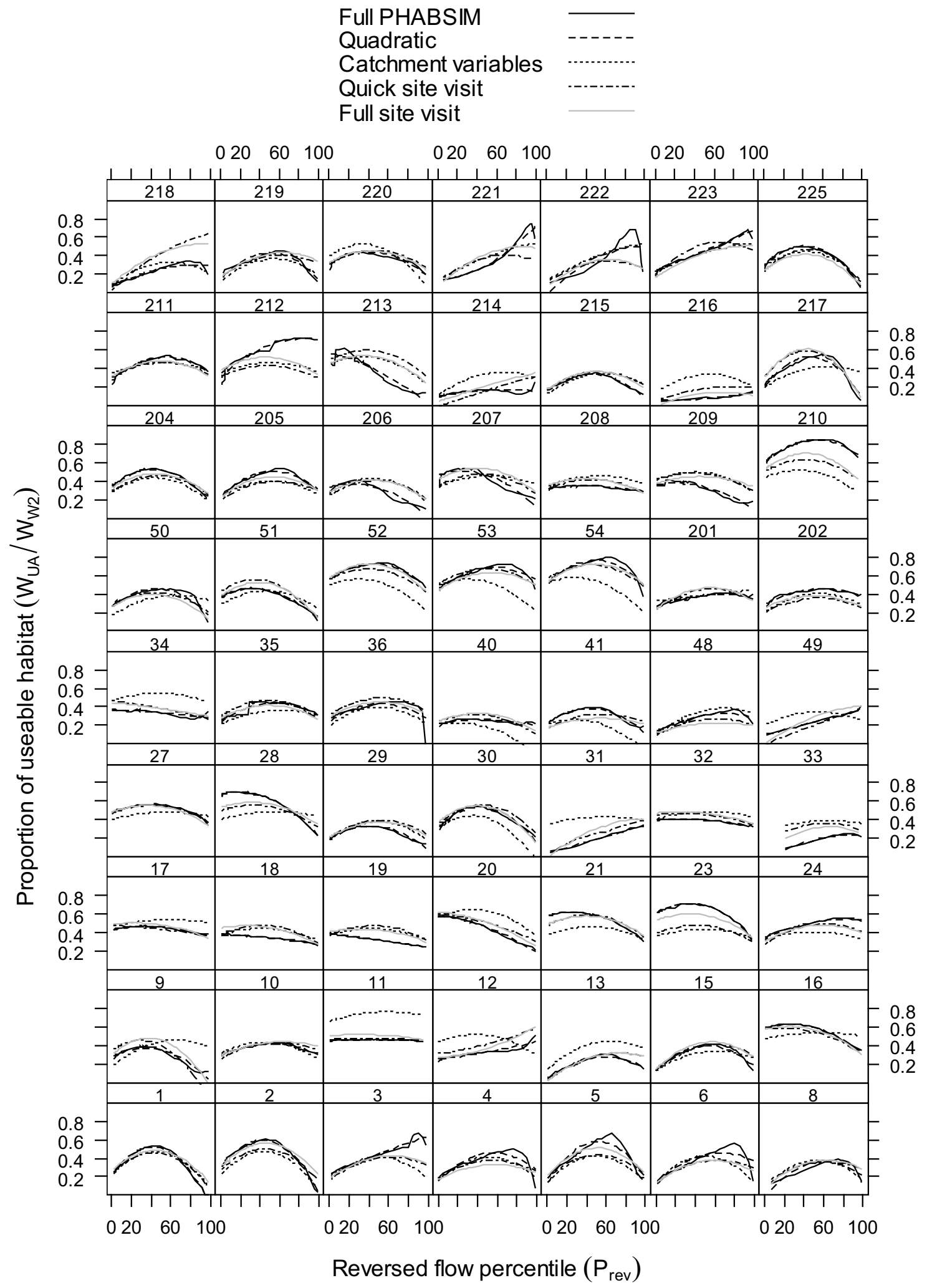

Fig. 8. Habitat-discharge relationships for HSII estimated using different levels of information. 
of the $W_{U A} / W_{W 2}$ v. $P_{r e v}$ curve is greatest using the Full set of hydraulic measurements rather than the Quick set or the catchment variables.

\section{MODEL EVALUATION}

Results from comparing model residuals with fitted values, and leverage with Cook's distance showed that some sites in the data set had a disproportionately large effect on the results when catchment variables were used to predict $a, b$, and $c$ (Fig. 9); for example, Sites 5 and 221 had a relatively large influence on the regressions because both these sites have relatively small catchments, low BFI, and low slope

Parameter b: Catchment variables

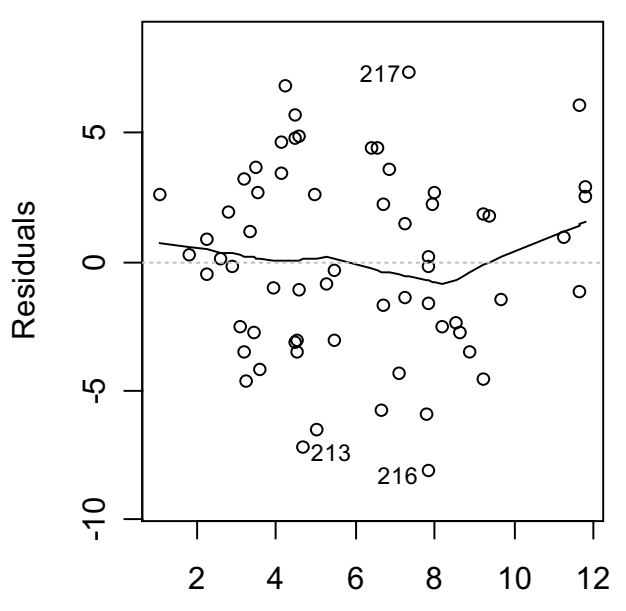

Fitted values

Parameter b: Cross-sectional Full Set

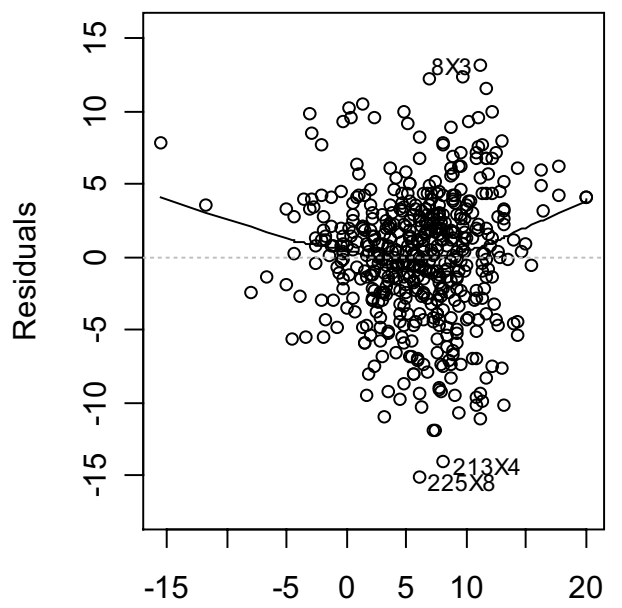

Fitted values but highly contrasting values of $b$.

Certain cross-sections also affected the results of the regressions more than others, because a small number of sites, or cross-sections, had a relatively large effect on the final model. For example, at the two fastest flowing and shallowest cross-sections at $\mathrm{Q}_{95}$, velocity was the limiting factor on habitat because almost all habitat was too fast to be deemed as suitable according to HSI1. Hence, these were cross-sections where depth had no influence on calculated WUA. Cross-section 1 at Site 220 had a high Cook's distance. This was a narrow cross-section with relatively fast velocities and deep depths. These outlying cross-

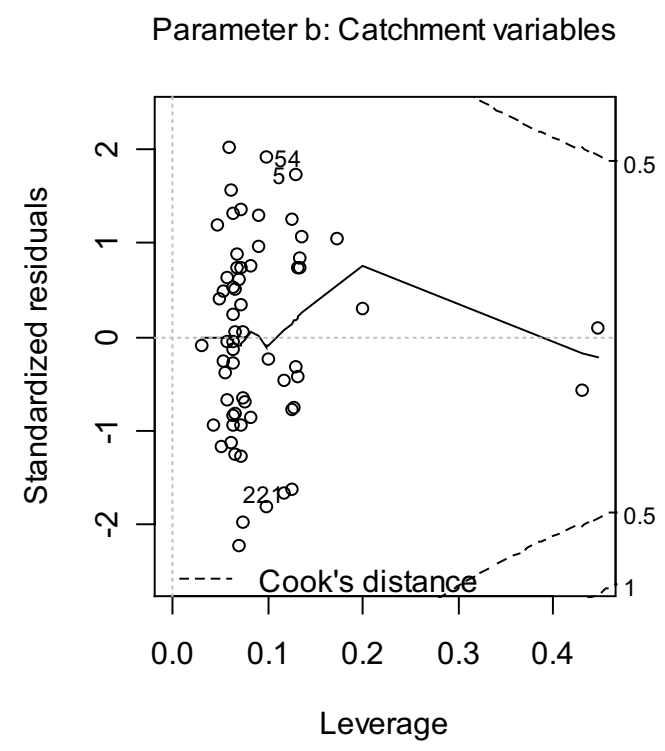

Parameter b: Cross-sectional Full Set

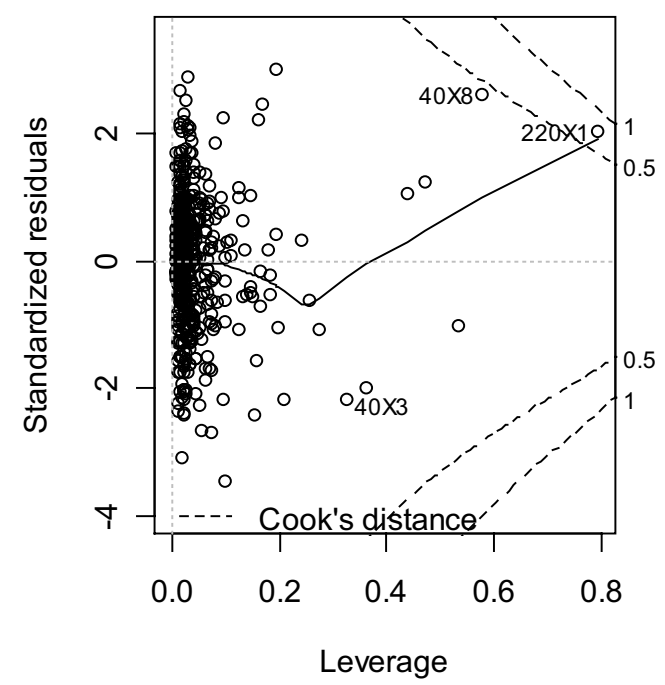

Fig. 9. Model diagnostics for when parameter a for HSIl was calculated from: top) catchment variables; bottom) the Full set of cross-sectional variables at $Q_{95}$. Sites with text show site number. Cross-sections with text show site number and cross-section number. 
sections represent departures from the standard bounds of relationships between width, depth, velocity and $W_{U A} / W_{W 2}$ v. $P_{\text {rev }}$ that were present within the database. In the majority of cross-sections, depth, velocity and width did relate to the calculated suitability. In addition, depth, velocity and width also influenced each other. However, in cross-sections with very fast velocities, depth and width had little effect on the $W_{U A} / W_{W 2}$ v. $P_{r e v}$ curves.

When run on randomly re-sampled datasets produced by bootstrap re-sampling, multiple regressions were more likely to have larger adjusted $r^{2}$ values (e.g. Fig. 10) and lower standard errors for both the catchment and cross-sectional data sets. This reflects the existence of some sites and crosssections with high leverages that represented the extremes of the relationships between the variables. There was greater spread in $\mathrm{r}^{2}$ values when catchment variables were used rather than cross-sectional data. This reflects the larger number of cross-sections compared with the number of sites and the stronger consistency in relationships between $b$ and cross-sectional rather than catchment variables.

Figure 11 shows how prediction of parameters $a, b$, and $c$ improves as more hydraulic variables are included in the stepwise regression. The order in which hydraulic variables were added to the regression reflects the time it would take to collect the required measurements in the field. For example, one measurement of maximum depth is quicker than measuring all depths across a cross-section, but measurements of depths across a cross-section allows subsequent calculation of area and channel asymmetry. Here the adjusted $r^{2}$ (Crawley, 2002) is used as a measure of uncertainty in the estimate of $a, b$ and $c$. Results show that there is little difference between the performance of the model derived using measurements made at $\mathrm{Q}_{95}$ and $\mathrm{Q}_{50}$. At

a) Catchment variables

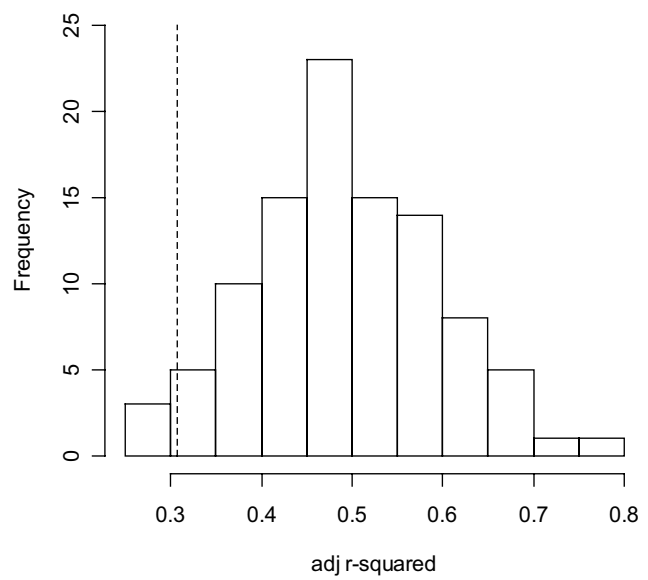

these flows, as more hydraulic information is known, the less uncertain are the estimates of $a, b$ and $c$. The rate of decrease in uncertainty of $a$ is relatively constant as information is added. This is not the case for $b$ and $c$. The greatest increase for these parameters comes with the addition of $V_{\text {max }}$ into the regression. Results show that when measurements are taken at $\mathrm{Q}_{2}$, the estimates of $a, b$ and $c$ are significantly more uncertain than for $\mathrm{Q}_{95}$ and $\mathrm{Q}_{50}$.

\section{Discussion}

A great deal of analysis of the relationships between catchment characteristics and hydrology has been undertaken during previous research aimed at producing methods for flood estimation at ungauged sites (Institute of Hydrology, 1999; Marshall, 2000), for water resources (Holmes et al., 2005) and for continuous hydrological simulation (Lee et al., 2006). In this paper, the utility of catchment characteristics to predict at-site physical habitatdischarge relationships was assessed and compared with that of cross-sectional information; the results show that estimation of $W_{U A} / W_{W 2}$ v. $P_{r e v}$ relationships using catchment characteristics can be improved using cross-sectional variables. This is probably due to the highly engineered nature of UK rivers' land drainage and flood defence no longer reflecting the character of their catchments (Raven et al., 1998; Sear et al., 2000).

Previous research to produce generalised approaches to habitat assessment have used whole site estimates (e.g. Lamouroux and Capra, 2002; Lamouroux and Jowett, 2005). Figure 5 shows that the form of the $W_{U A} / W_{W 2} v . P_{r e v}$ relationships can vary considerably between cross-sections at the same site. Results presented here have shown that

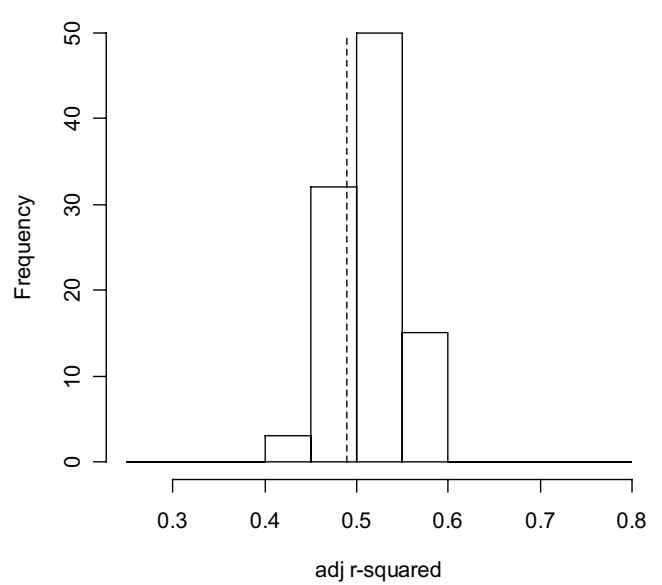

Fig. 10. Distribution of adjusted $r^{2}$ values when parameter a for HSII was calculated from the Full set of variables using 100 bootstrap resamples. Dotted line indicates position of adjusted $r$-squared value for the original data set. 

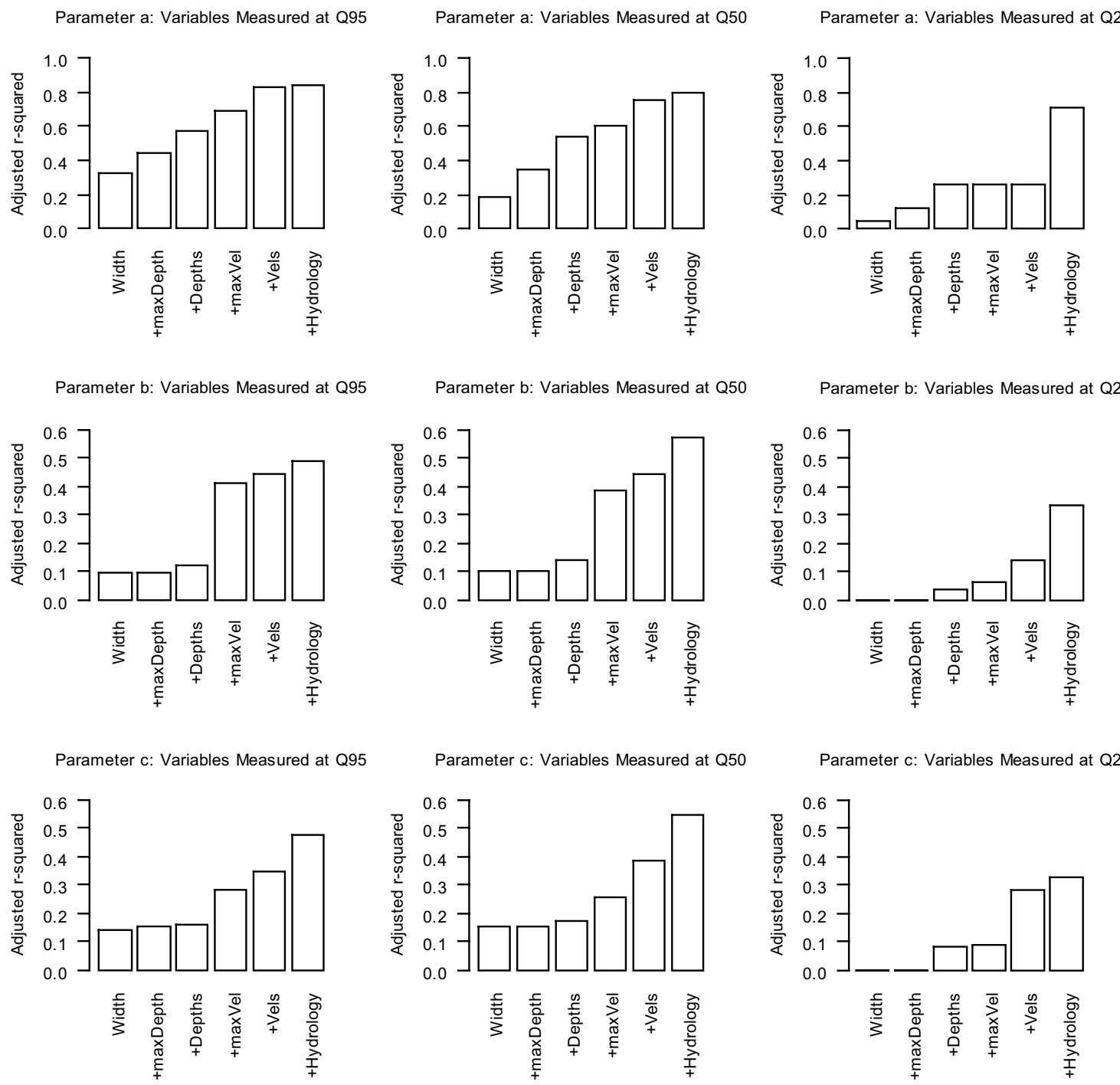

Fig. 11. Adjusted r-squared values for habitat predicted for HSII when progressively more hydraulic information is known, for three separate flows $\left(\right.$ Width $=\mathrm{W}_{\mathrm{W}}, \mathrm{W}_{\mathrm{W} 2} ;+$ maxDepth $=$ addition of $\mathrm{D}_{\max } ;+$ Depths $=$ addition of $\mathrm{D}, \mathrm{A}_{1}, \mathrm{~A}_{\mathrm{sym} 1}, \mathrm{~A}_{\mathrm{sym} 2} ;+$ maxVel $=$ addition of $\mathrm{V}_{\max } ;+$ Vels $=$ addition of $\mathrm{V}, \mathrm{F}, \mathrm{R} ;+$ Hydrology $=$ addition of $\left.Q_{95}, Q_{50}, Q_{2}\right)$.

stronger relationships between hydraulic variables and the form of habitat-discharge curves can be derived by analysing data separately for individual cross-sections. Results for all cross-sections at a site can subsequently be amalgamated to give whole site predictions. This provides a more flexible method that can be applied to sites with both homogeneous and heterogeneous channel morphology.

The database for this project included data from PHABSIM studies applied at 63 sites in the UK. This is not an unbiased sample of UK rivers. The majority of these sites represent wadeable reaches (i.e. less than $1 \mathrm{~m}$ deep) with either trout or salmon populations. Furthermore, PHABSIM studies are most often applied to rivers that are thought to be adversely affected by abstraction. Therefore, larger rivers are under-represented and high baseflow sites (Chalk rivers in south-east England) may be over-represented in the database as a whole. However, the database does contain a mix of upland and lowland sites, as well as sites from both rural and urban locations and with both permeable and impermeable geologies. The size of the dataset meant that split sample testing of models was not appropriate.

The method employed here was to analyse the empirical relationship between hydraulics at a specified flow and the form of the physical habitat-discharge relationship. The analysis employs a statistical approach and does not assess in detail the hydraulic processes that control the relationship between discharge and hydraulics or the ecological processes that control the relationship between discharge and habitat suitability. This is an advantage to the method, because depth, velocity and width can all affect habitat, but these 
variables also have complex interactions with each other as discharge increases.

This approach assumes that the mechanisms for defining physical habitat are the same for all cross-sections within the database, i.e. habitat is controlled by width, depth and velocity (and the interactions between width, depth and velocity). The method has the potential to be less certain at cross-sections where exceptional hydraulic conditions are present, specifically, the presence of narrow cross-sections with fast, deep flowing water. This aspect of the method implies that extrapolation to cross-sections exhibiting conditions outside the range of the present database could be less reliable. However, it should be noted that, of the ten cross-sections with the largest residuals, nine were from different sites. This supports the theory that the method is less certain at specific cross-sections rather than at all crosssections from a particular site.

Hydraulic models were used to simulate a suite of hydraulic variables over a range of flows for all sites. This allowed extraction and analysis of the hydraulic conditions for all cross-sections at a single standardised flow. These data were then used as a substitute for field data collected at the sites. Any errors that may have resulted from the hydraulic modelling process will affect the final results.

Results from PCA and hierarchical partitioning analysis showed that considerable collinearities exist within the suite of both the catchment and hydraulic variables used, so that some variables could be substituted for others without significant loss of overall explanatory power. Within the cross-sectional data, strong relationships between maximum velocity, velocity, Froude number and Reynolds number were particularly evident with respect to $b$ and $c$. These collinearities did not always act in the same manner, depending on whether they were being used to predict $a, b$ or $c$. Under certain circumstances, some pairs of hydraulic variables were found to have counteracting relationships with respect to $a, b$ and $c$. This situation may occur where two hydraulic variables have a positive relationship with each other and the first hydraulic variable has a positive relationship with the variable being predicted, while the second hydraulic variable has a negative relationship with the response variable. Results from the PCA also showed that parameter $a$, which determines the proportion of suitable habitat at low flows, was well correlated with scale dependent hydraulic variables such as width and discharge. This supports previous work suggesting that there is a greater proportion of suitable habitat in larger rivers (Beecher, 1990), in accordance with the findings of Jowett et al. (1998) who showed similar results for rivers in New Zealand.

In this paper, the method was demonstrated using results from one life-stage of one species; HSI1 (juvenile salmon).
However, the method is generic and can be applied to different species and different life stages (e.g. Fig. 4). In this paper, the method was applied for 10 fish HSIs but it could be applied to other species, including invertebrates and plants that are responsive to changes in physical habitat.

One advantage of the method is that statistical summaries are used to provide a measure of uncertainty for the estimate of sensitivity to abstraction. This allows an assessment of the trade-off between the effort required to collect field data and reduction in the uncertainty in the estimate of sensitivity to abstraction, because the method allows for a reduction in uncertainty as more detailed hydraulic information is collected. This fits well with the risk-based approach (Faulkner et al., 2004) adopted by the Environment Agency to assess environmental impact of abstractions in England and Wales. The risk-based approach involves using the simplest approach that gives an acceptable level of certainty given the risk of being wrong. More complex models are employed if the results are too uncertain and the risk is too great. The basic rule is that the model must be fit for purpose; the purpose depends on the risk, e.g. specially designated sites require a higher level of confidence in results.

\section{Conclusion}

This paper demonstrates that relationships between catchment characteristics and habitat are available for different target fish species. Stronger relationships exist at the cross-sectional scale between single measurements of channel form, river hydraulics and the habitat available for target species. The results can form the basis of a method to estimate sensitivity of physical habitat to flow change by visiting a site at only a single flow. There is little difference in the reliability of these estimates between $\mathrm{Q}_{95}$ and $\mathrm{Q}_{50}$, and the uncertainty of the estimate is reduced as hydraulic information is added to the analysis. The greatest reduction in uncertainty is gained with measurement of maximum velocity at a cross-section. This is because there are strong collinearities within the hydraulic variables that could be measured at a site. This is particularly the case for variables, such as Reynolds Number, Froude Number and channel asymmetry, which are calculated from simple field measurements but is also true for maximum and mean velocity, and for maximum and mean depth. The increase in reliability of estimates as more information is collected, defines a risk-based approach that allows the user to select the appropriate level of investment in data collection for the desired confidence in the results. 


\section{Acknowledgements}

The research reported in this paper was funded jointly by the Environment Agency (W6-094) and the Natural Environment Research Council (C02947T1).

\section{References}

Acreman, M.C. and Elliott, C.R.N., 1996. Evaluation of the river Wey restoration project using the Physical HABitat SIMuation (PHABSIM) model. Proc. MAFF Conference of River and Coastal Engineers, Keele, 3-5 July, 1996.

Acreman, M.C., Dunbar, M.J., Hannaford, J., Black, A., Bragg, O., Rowan, J. and King, J., 2005. Development of environmental standards (Water Resources). Stage 3: Environmental Standards. Report to the Scotland and Northern Ireland Forum for Environment Research. Centre for Ecology and Hydrology, Wallingford, UK and University of Dundee, Dundee, UK.

Armitage, P.D. and Ladle, M., 1991. Habitat preferences of Target Species for application in PHABSIM testing, In: Instream Flow Requirements of Aquatic Ecology in Two British Rivers, A.Bullock, A.Gustard and E.S.Grainger, (Eds.). IH Report No. 115, Institute of Hydrology, Wallingford, UK.

Beecher, H.A., 1990. Standards for instream flows. Rivers, 1, 97-109.

Beecher, H.A., Johnson, T.H. and Carleton, J.P., 1993. Predicting microdistributions of steelhead (Oncorhynchus mykiss) parr from depth and velocity preference criteria: test of an application of the Instream Flow Incremental Methodology. Can. J. Fisheries Aquat. Sci., 50, 2380-2387.

Belsley, D.A., Kuh, E. and Welsch, R.E., 1980. Regression Diagnostics: Identifying Influential Data and Sources of Collinearity. Wiley, New York, USA. 320pp.

Booker, D.J. and Dunbar, M.J., 2004. Application of Physical HAbitat SIMulation (PHABSIM) modelling to modified urban river channels. River Res. Appl., 20, 167-183.

Booker, D.J., Dunbar, M.J. and Ibbotson, A.T., 2004. Predicting juvenile salmonid drift-feeding habitat quality using a threedimensional hydraulic-bioenergetic model. Ecol. Model., 177, 157-177.

Bovee, K.D., 1982. A guide to stream habitat analysis using the IFIM. US Fish and Wildlife Service Report FWS/OBS-82/26. Fort Collins, USA.

Bovee, K.D., Lamb, B.L., Bartholow, J.M., Stalnaker, C.B., Taylor, J. and Henriksen, J., 1998. Stream habitat analysis using the Instream Flow Incremental Methodology. US Geological Survey, Biological Resources Division, Information and Technology Report USGS/BRD-1998-0004. 139pp.

Capra, H., Sabaton, C., Gouraud, V., Souchon, Y. and Lim, P., 2003. A population dynamics model and habitat simulation as a tool to predict brown trout demography in natural and bypassed stream reaches. River Res. Appl., 19, 551-568.

Cavendish, M.G. and Duncan, M.I., 1986. Use of the instream flow incremental methodology; a tool for negotiation. Environ. Impact Assess. Rev., 6, 347-363.

Chevan, A. and Sutherland, M., 1991. Hierarchical partitioning. Amer. Statist., 45, 90-96.

Crawley, M.J., 1993. GLIM for Ecologists. Blackwell Science, Oxford, UK. 379pp.

Crawley, M.J., 2002. Statistical computing: an introduction to data analysis using S-Plus. Wiley, Chichester, UK. 761pp.

Davison, A.C. and Hinkley, D.V., 1997. Bootstrap methods and their application. Cambridge University Press, Cambridge, UK. $582 \mathrm{pp}$.
Dawson, F.H., Hornby, D.D. and Hilton, J., 2002. A method for the automated extraction of environmental variables to help the classification of rivers in Britain. Aquat. Conserv-Mar. Freshwater Ecosyst., 12, 391-403.

Dunbar, M.J. and Acreman, M.C., 2001. Applied hydro-ecological science for the twenty-first century. IAHS Publication no. 266, $1-18$.

Dunbar, M.J., Gowing, I.M. and Linstead, C., 2000. PHABSIM investigations on the River Wylye: PHABSIM model calibration and time series analysis. Report to Environment Agency Contract SWCON61, Institute of Hydrology, Wallingford, UK.

Dunbar, M.J., Ibbotson, A.T., Gowing, I.M., McDonnell, N., Acreman, M.C. and Pinder, A., 2001. Ecologically acceptable flows Phase III: further validation of PHABSIM for the habitat requirements of salmonid fish. Final R\&D Technical report to the Environment Agency. 136pp.

Eisner, A., Young, C., Schneider, M. and Kpoecki, I., 2005. MesoCASiMiR - new mapping method and comparison with other current approaches. COST 626 Proceedings from the final meeting in Silkeborg, Denmark, 19-20 May 2005.

Elliott, C.R.N., Johnson, I.W., Sekulin, A.E., Dunbar, M.J. and Acreman, M.C., 1996. Guide to the use of the Physical Habitat Simulation System. Report to National Rivers Authority. Institute of Hydrology, Wallingford, UK. 87pp.

Elliott, C.R.N., Dunbar, M.J., Acreman, M.C. Gowing, I.M., Ibbotson, A. and Linstead, C., 1999. Application of the Physical Habitat Simulation (PHABSIM) system to rivers of Scotland and Northern Ireland. Report to the Scotland and Northern Ireland Forum for Environmental Research. Institute of Hydrology, Wallingford, UK.

Environment Agency, 2002. Managing Water Abstraction, the Catchment Abstraction Management Process. Available from http://www.environment-agency.gov.uk/commondata/105385/ mwa english.pdf

Faulkner, D., Maudsley, J., Brassington, F., Boak, R., Fletcher, S., Johnson, D. and Evers, S., 2004. Risk-based decision-making for water resources licensing. Phase 2: Guidance on conducting a hydro-geological impact appraisal. R\&D Technical Report W6-071/TR2. Environment Agency Bristol, UK.

Gallagher, S.P. and Gard, M.F., 1999. Relationship between Chinook salmon (Oncorhynchus tshawytscha) redd density and PHABSIM-predicted habitat in the Merced and Lower American rivers, California. Can. J. Fisheries Aquat. Sci., 56, 570-577.

Giller, P.S. and Malmqvist, B., 1998. The biology of streams and rivers. Oxford University Press, Oxford, UK.

Ginot, V., 1995. EVHA, Un logiciel d'evaluation de l'habitat du poisson sous Windows. Bull. Fr. Peche Pisic., 337/338/339, 303-308.

Gore, J.A., Crawford, D.J. and Addison, D.S., 1998. An analysis of artificial riffles and enhancement of benthic community diversity by physical habitat simulation (PHABSIM) and direct observation. Regul. River., 14, 69-77.

Greenberg, L.A. and Giller, P.S., 2001. Individual variation in habitat use and growth of male and female brown trout. Ecography, 24, 212-224.

Hatt, B.E., Fletcher, T.D., Walsh, C.J. and Taylor, S.L., 2004. The influence of urban density and drainage infrastructure on the concentrations and loads of pollutants in small streams. Environ. Manage., 34, 112-124.

Hearne, J., Johnson, I.W. and Armitage, P.D., 1994. Determination of eceologically acceptable flows in rivers with seasonal changes in the density of macrophyte. Regul. River., 9, 117-184.

Holmes, M.G.R., Young, A.R., Gustard, A. and Grew, R., 2002a. A region of influence approach to predicting flow duration curves within ungauged catchments. Hydrol. Earth Syst. Sci., 6, 721-731. 
Holmes, M.G.R., Young, A.R., Gustard, A. and Grew, R., 2002 b. A new approach to estimating mean flow in the UK. Hydrol. Earth Syst. Sci., 6, 709-720.

Holmes, M.G.R., Young A.R., Goodwin, T.H. and Grew, R., 2005. A catchment-based water resource decision-support tool for the United Kingdom. Environ. Model. Software, 20, 197-202.

Hughes, N.F., 1992. Selection of positions by drift-feeding salmonids in dominance hierarchies - model and test for Arctic grayling (thynallus arcticus) in sub-arctic mountain streams, interior Alaska. Can. J. Fisheries Aquat. Sci., 49, 1999-2008.

Hynes, H.B.N., 1970. The ecology of running waters. University of Toronto Press, Canada.

Institute of Hydrology, 1999. Flood estimation handbook. 5 vols, Institute of Hydrology, Wallingford, UK.

Johnson, I.W., Elliott, C.R.N., Gustard, A., Armitage, P.D., Ladle, M., Dawson, F.H. and Beaumont, W., 1993. Ecologically acceptable flows, National Rivers Authority R\&D Project Record 282/1/Wx, Bristol, UK.

Johnson, I.W., Elliott, C.R.N. and Gustard, A., 1995. Modelling the effect of groundwater abstraction on salmonid habitat availability in the River Allen, Dorset, England. Regul. River., 10, 229-238.

Jorde, K., 1996. Ecological evaluation of Instream Flow Regulations based on temporal and spatial variability of bottom shear stress and hydraulic habitat quality. In: Ecohydraulics 2000, $2^{\text {nd }}$ International Symposium on Habitat Hydraulics, M. Leclerc et al. (Eds.) Quebec City, Canada.

Jowett, I.G., 1989. River hydraulic and habitat simulation, RHYHABSIM computer manual. New Zealand fisheries miscellaneous Report 49. Ministry of Agriculture and Fisheries, Christchurch, New Zealand. 39pp.

Jowett, I.G., 1990. Factors related to the distribution and abundance of brown and rainbow trout in New Zealand clear-water rivers. N. Z. J. Mar. Freshwater Res., 24, 429-440.

Jowett, I.G., 1992. Models of the abundance of large brown trout in New Zealand rivers. N. Amer. J. Fisheries Manage., 12, 417432.

Jowett, I.G., Hayes, J.W., Deans, N. and Eldon, G.A., 1998. Comparison of fish communities and abundance in unmodified streams of Kahurangi National Park with other areas of New Zealand. N. Z. J. Mar. Freshwater Res., 32, 307-322.

Junk, W.J., Bayley, P.B. and Sparks, R.E., 1989. The flood pulse concept in river-floodplain systems. Can. J. Fisheries Aquat. Sci., 106, 110-127.

Kennard, N.R., 2000. Development and testing of a rapid assessment methodology for instream habitat. MSc Thesis. Utah State University, Logan, USA.

Killingtviet, Å. and Harby, A., 1994. Multi purpose planning with the River System Simulator - a decision support system for water resources planning and operation. In: Proceedings of the First International Symposium on Habitat Hydraulics, Norwegian Institute of Technology, Trondheim, Norway.

Lamouroux, N. and Capra, H., 2002. Simple predictions of instream habitat model outputs for target fish populations. Freshwater Biol., 47, 1543-1556.
Lamouroux, N. and Jowett, I.G., 2005. Generalized instream habitat models. Can. J. Fisheries Aquat. Sci., 62, 7-14.

Lee, H., McIntyre, N.R., Wheater, H.S. and Young, A.R., 2006. Predicting runoff in ungauged UK catchments. Proc. Inst. Civil Eng.-Water Manage., 159, 129-138.

MacNally, R., 2000. Regression and model-building in conservation biology, biogeography and ecology: The distinction between and reconciliation of 'predictive' and 'explanatory' models. Biodivers. Conserv., 9, 655-671.

Maddock, I., 1999. The importance of physical habitat assessment for evaluating river health. Freshwater Biol., 41, 373-391.

Marshall, D.C.W., 2000. The estimation of flood-response times from digital catchment data. J. Chart. Inst. Water Env. Manage., 14, 335-340.

Mathur, D., Bason W.H., Purdy, E.J. and Silver, C.A., 1985. A critique of the instream flow incremental methodology. Can. J. Fisheries Aquat. Sci. 42, 825-831.

McPherson, J.I., 1997. Appeal by Thames Water Utilities under Section 43 of the Water Resources Act 1991, S: Inspector's Report, refWAT/95/22. Department of the Environment, Bristol, UK. $143 \mathrm{pp}$.

Metcalfe, N.B., Valdimarsson, S.K. and Fraser, N.H.C., 1997. Habitat profitability and choice in a sit-and-wait predator: juvenile salmon prefer slower currents on darker nights. J. Anim. Ecol., 66, 866-875.

Milne, J.A., 1983. Variation in cross-sectional asymmetry of coarse bedload river channels. Earth Surf. Process. Landf., 8, 503511.

Norris, R.H. and Thoms, M.C., 1999. What is river health? Freshwater Biol., 41, 197-209.

Orth, D.J., 1986. In defense of the Instream Incremental Methodology. Can. J. Fisheries Aquat. Sci., 43, 1092.

Poff, N.L., Allan, J.D., Bain, M.B., Karr, J.R., Prestegaard, K.L., Richter, B.D., Sparks, R.E. and Stromberg, J.C., 1997. The natural flow regime. Bioscience, 47, 769-784.

Raven, P.J., Holmes, N.T.H., Dawson, F.H., Everard, M., Fozzard, I.R. and Rouen, K.J., 1998. River habitat quality: the physical character of rivers and streams in the UK and Isle of Man. River Habitat Survey Report No. 2. Environment Agency, Bristol. ISBN 173160429.

Reiser, D.W., Wesche, T.A. and Estes, C., 1989. Status of instream flow legislation and practices in North-America. Fisheries, 14, $22-29$.

Richter, B.D., Baumgartner, J.V., Wigington, R. and Braun, D.P., 1997. How much water does a river need? Freshwater Biol., 37, 231-249.

Sear, D., Wilcock, D., Robinson, M. and Fisher, K., 2000. River channel modification in the UK. In: The hydrology of the UK: a study of change, M.C. Acreman (Ed.), Routledge, London, UK. 48-59.

Strevens, A.P., 1999. Impacts of groundwater abstraction on the trout fishery of the River Piddle; and an approach to their alleviation. Hydrol. Process., 13, 487-496.

Venables, W.N. and Ripley, B.D., 2002. Modern applied statistics with $S$. Springer, New York, USA. 